Кучаев В. А.

ИСТОРИЧЕСКИЙ ОПЫТ И ЕГО ЗНАЧЕНИЕ В СОЗДАНИИ, СТАНОВЛЕНИИ И РАЗВИТИИ СИСТЕМЫ

ПОДГОТОВКИ ОФИЦЕРОВ ЗАПАСА В РОССИИ НА СОВРЕМЕННОМ ЭТАПЕ ЕЁ РЕФОРМИРОВАНИЯ

Кучаев В. А.

V. A. Kuchaev

ИСТОРИЧЕСКИЙ ОПЫТ И ЕГО ЗНАЧЕНИЕ В СОЗДАНИИ, СТАНОВЛЕНИИ

И РАЗВИТИИ СИСТЕМЫ ПОДГОТОВКИ ОФИЦЕРОВ ЗАПАСА В РОССИИ

НА СОВРЕМЕННОМ ЭТАПЕ ЕЁ РЕФОРМИРОВАНИЯ

\title{
HISTORICAL EXPERIENCE AND ITS IMPORTANCE IN CREATING AND DEVELOPMENT OF RESERVE OFFICERS' TRAINING SYSTEM IN RUSSIA AT THE PRESENT STAGE OF REFORM
}

Кучаев Валентин Александрович - начальник учебной части, заместитель начальника военной кафедры при Комсомольском-на-Амуре государственном университете (Россия, Комсомольск-на-Амуре); 681013, Хабаровский край, Комсомольск-на-Амуре, пр. Ленина, 27; тел.: + 7 (4217) 24-12-05. Е-таil: v.ku4@yandex.ru.

Mr. Valentin A. Kuchaev - Head of Training Department, Deputy Head of Military Department, Komsomolskon-Amur State University (Russia, Komsomolsk-on-Amur); 681013, Khabarovsk territory, Komsomolsk-on-Amur, 27 Lenin str.; tel.: + 7 (4217) 24-12-05. E-mail: v.ku4@yandex.ru.

Аннотация. В предлагаемой работе представлена краткая история возникновения, становления и эволюции подготовки офицеров запаса в гражданских учебных заведениях; определены её основные исторические этапы. Проанализирована логика развития системы военной подготовки в вузах, сформулированы исторические и современные условия, определяющие необходимость проведения реформы.

Summary. The paper presents a brief history of the occurrence, formation and development of the training system of reserve officers in civilian educational institutions; and defines the main historical stages. The logic of development of the military training system in universities is analyzed and historical and modern conditions, that determine the need for reform, are emphasized.

Ключевые слова: военная подготовка, офицеры запаса, военные кафедры, вузы.

Key words: military training, reserve officers, military departments, universities.

УДК: 355.237.084.92

В настоящее время по инициативе Министерства обороны Российской Федерации в стране проводится очередная (постсоветского времени) реформа системы военной подготовки при гражданских вузах [1].

Основная идея реформы - унификация подходов и способов реализации военной подготовки в высших учебных заведениях (создание военных учебных центров взамен военных кафедр, факультетов военного образования и учебных военных центров) [2].

Указанные изменения с момента внесения законодательной инициативы [3] вызывают в обществе повышенный интерес, они также спровоцировали оживлённые дискуссии о необходимости проведения реформы военной подготовки при гражданских вузах вообще и о возможных других вариантах и направлениях реформирования в частности. По мнению экс-депутата Государственной думы Российской Федерации (депутата третьего и четвёртого созывов) полковника в отставке В. И. Алксниса, «закрытие военных кафедр приведёт к сокращению числа офицеров запаса» [4]. Но выпускники военных кафедр, пополняя мобилизационный запас страны, становятся более востребованными на действительной военной службе по контракту. В большей мере этот факт обусловлен «кадровым голодом», связанным с реорганизацией в 2007-2012 годах (фактически - с ликвидацией) многих военных училищ и военных академий. Учитывая это, Министерство обороны Российской Федерации ставит целью проводимой реформы повышение эффективности управления процессом обучения студентов вузов по имеющимся направлениям военной подготовки [3]. 


\section{Учёные записки}

Комсомольского-на-Амуре государственного технического университета

Система военной подготовки в гражданских вузах, сложившаяся к 2018 году в Российской Федерации, имеет давнюю и богатую историю зарождения, эволюционного развития и множественных преобразований. Военная подготовка в общей системе образования находится на пересечении высшего и военного образования, является их частью. По этой причине некоторые авторы, в частности С. М. Фильков, С. А. Сацута, оценивают и формулируют исторические этапы подготовки офицеров запаса, начиная с VI-VII века, когда только начинала формироваться некая система накопления и распространения необходимых для военного дела знаний - начальный этап появления русского государства и общества.

Таким образом, С. М. Фильков, ссылаясь на исторический опыт подготовки отечественных военных кадров, представленный в разных источниках $[5 ; 6 ; 7]$, предлагает историческую периодизацию в соответствии с особыми социально-экономическими, социально-политическими, социально-культурными и военно-политическими условиями развития России на следующих этапах развития системы военной подготовки в гражданских вузах [8].

I этап. Зарождение и возникновение системы (с начала становления русского государства и до рубежа XVII-XVIII вв.). Это этап накопления, сохранения и распространения особых знаний, умений и опыта в военном деле. На этом же этапе возникают в X веке первые русские школы, «книжное учение» которых формировало, говоря современным языком, компетенции, в том числе необходимые и воину.

Вопросы военного дела входили в подготовку и обучение при монастырях, а также в профессионально-ремесленном и индивидуальном обучении в период формирования и укрепления централизованного русского государства. В XIV-XVII вв. выходцы из различных слоёв российского общества, получив образование, принимались на службу в княжеские дружины, а с появлением регулярного войска служили стрельцами или даже предводителями отрядов.

Примером обобщения и сохранения специальных знаний военного дела служит составленный в начале XVII века Анисимом Михайловым «Устав ратных, пушечных и других дел [9].

II этап. Раннее (дореволюционное) становление (с рубежа XVII-XVIII вв. и до 1917 года). Военная подготовка в различных её формах присутствовала в гражданских вузах с рубежа XVII-XVIII вв., когда в ходе реформ Петра I в Российском государстве зародилась система высшего и специального профессионального образования.

Позднее, к XIX веку, в России создаётся система учебных заведений: университетов и институтов, различных школ и училищ, юнкерских и военных училищ, а также кадетских корпусов. Эти учебные заведения готовили компетентных специалистов, готовых трудиться в том числе (по желанию) и на военной службе.

До 1917 года выпускники гражданских учебных заведений систематически пополняли офицерский корпус царской армии, формировали мобилизационный резерв. Дворянское и другие сословия могли быть привлечены к гражданской или военной службе, быть зачисленными в резерв различными способами:

- после прохождения дополнительного краткосрочного обучения в кадетских корпусах;

- после окончания университета (по представлению руководства учебного заведения) лучшим студентам присваивались воинские звания; таких выпускников приписывали к воинским подразделениям с предоставлением возможности поступления на военную службу.

Вместе с тем техническое оснащение армии росло, усложнялись инженерные и артиллерийские оборудование и приборы, появлялись новые виды оружия и оснащение войск. Это обусловило создание новых кадетских корпусов в Санкт-Петербурге и Москве, выпускавших как кадровых офицеров, так и офицеров запаса командно-инженерных специальностей.

Военная подготовка становилась обязательной для всех студентов всех высших учебных заведений в военные периоды дважды: в XIX веке - в годы Крымской и Русско-турецкой войн, и в XX веке - во время Русско-японской войны. В эти периоды практически все выпускники вузов получали офицерские звания. Выпускники гражданских вузов принимали участие во всех военных кампаниях этого времени, командуя вверенными подразделениями наряду с кадровыми военными на различных офицерских должностях. Максимальное количество не только выпускников вузов, 
Кучаев В. А.

ИСТОРИЧЕСКИЙ ОПЫТ И ЕГО ЗНАЧЕНИЕ В СОЗДАНИИ, СТАНОВЛЕНИИ И РАЗВИТИИ СИСТЕМЫ

ПОДГОТОВКИ ОФИЦЕРОВ ЗАПАСА В РОССИИ НА СОВРЕМЕННОМ ЭТАПЕ ЕЁ РЕФОРМИРОВАНИЯ

но и студентов было призвано на офицерские должности в годы Первой мировой войны. Количество вольноопределяющихся в офицерском корпусе российской армии доходило до 75 \% [10].

Окончание II этапа развития системы военной подготовки в гражданских вузах обусловлено рядом катастрофических по своей разрушающей мощи событий: Первая мировая война, Февральская и Октябрьская революции 1917 года, Гражданская война 1918-1922 годов.

Военная подготовка при гражданских вузах, не завершённая в своей структуре, не состоявшаяся как устойчивая и цельная система, была уничтожена вместе с государственностью царской России.

III этап. Восстановление системы и её развёртывание в советское время (с середины 20-х до конца 80-х гг. XX века). Реалии жизни и времени продиктовали необходимость создания в Советском Союзе системы высшего образования. Фактически возрождение (восстановление) военной подготовки студентов началось с организации высшей допризывной военной подготовки. Создаются военные кабинеты, назначенные обеспечить подготовку граждан в рамках обязанностей и навыков младших командиров.

Военные кабинеты в 1930 году преобразовываются в военные кафедры и вводится высшая вневойсковая подготовка, при этом обучение на военной кафедре засчитывалось как служба в армии. Выпускники военных кафедр по окончании вуза зачислялись в резерв офицерского состава. В зависимости от специализации университета (института) офицеры запаса имели медицинские, технических, химические специальности или имели пехотный (командный) профиль.

К 1940 году военные кафедры преобразовываются в кафедры военно-физической подготовки, основной задачей которых становится начальная военная подготовка. По окончании вуза выпускники кафедры военно-физической подготовки должны были пройти действительную военную службу.

С началом Великой Отечественной войны воссоздание системы подготовки военных кадров в гражданских вузах сыграло значительную роль в обеспечении проведения мобилизации. Только в первый месяц войны было призвано 650 тыс. офицеров запаса, значительная часть которых была подготовлена в гражданских вузах [8]. К концу войны военные кафедры в вузах стали восстанавливаться, основной их задачей вновь становилась военная подготовка офицеров запаса.

В послевоенные годы в силу различных причин как объективного (внешнеполитическая обстановка, цели военного строительства и внутреннего развития страны), так и субъективного характера (цели и направления внутренней и внешней политики после смерти И. В. Сталина были существенно изменены), содержание и организация системы военного обучения студентов неоднократно изменялись и уточнялись. В 60-70-е годы XX века в Советском Союзе сформировалась мощная (более 500 военных кафедр и факультетов) система военной подготовки при вузах. Несмотря на масштабность, эта система была чётко отлажена и скоординирована по всем функциональным вопросам. Выпускники гражданских вузов стали призываться для прохождения службы в Советской армии и Военно-морском флоте СССР на офицерских должностях, некоторые оставались для прохождения кадровой службы.

По причине действия непреодолимых, как впоследствии оказалось, сил, ведущего к уничтожению Советского государства, система военной подготовки офицеров запаса в 80-е годы вошла в кризисное состояние. Насколько объективно была нужна в стране провозглашённая М. С. Горбачевым перестройка - мнений много на этот счёт, но проводилась она также и в отношении высшего образования, и в плане перестройки системы военной подготовки на военных кафедрах. Итог в той или иной мере напоминает окончание II периода - уничтожение государства, уничтожение (правда, не тотальное, но с «мутациями деструктивного характера» в эволюции) системы высшего образования в целом, системы военной подготовки офицеров запаса в частности. Эти регрессивные процессы мы отнесём уже к IV этапу.

IV этап. Реформирование сложившейся в советское время системы, или Современный этап развития, начавшийся в конце 80-x - начале 90-х годов XX века. С начала этого периода и по настоящее время не прекращается постоянное реформирование системы военной подготовки в вузах. Противоречивый характер проводимых преобразований, с одной стороны, обусловлен 


\section{Учёные записки}

Комсомольского-на-Амуре государственного технического университета

№ 01-2(38) 2019

неоднозначностью происходящих на постсоветском пространстве процессов, с другой стороны явлениями дисбаланса в мировой политике.

С началом реформ, после некоторых попыток структурных преобразований, в том числе и на основе зарубежного опыта, в центральных вузах страны директивными указаниями Правительства Российской Федерации и министерств, курирующих деятельность вузов (Минобрнауки, Минобороны, Минздрав), были запущены ликвидационные механизмы системы подготовки офицеров запаса. В 1993 году было сокращено более двух третьих общего количества военных кафедр при гражданских образовательных учреждениях (с 252 до 81 военной кафедры).

Подходы органов государственного и военного управления Российской Федерации к организации военной подготовки в гражданских вузах с конца 90-х и в первом десятилетии 2000-х постоянно менялись. При этом необходимо отметить положительные стороны развития этих событий:

1. В результате анализа происходящих на стыке веков событий в ходе систематического поиска пришло осмысление необходимости сохранения системы подготовки офицеров запаса в гражданских вузах.

2. Наметился курс на формирование и совершенствование законодательной базы, стала создаваться внятная правовая основа создания и функционирования системы военного обучения при гражданских вузах.

3. В государстве появились средства для материальной поддержки и обеспечения военного образования.

Промежуточным результатом реформирования явилось создание в 2008 году наряду с военными кафедрами и факультетами военного образования учебных военных центров [11]. Всего 37 военных факультетов и кафедр (всего было около 250) преобразованы в учебные военные центры. Выпускники военных учебных центров по завершении обучения в вузе обязаны поступить на военную службу по контракту на воинских должностях, подлежащих замещению офицерами [12].

В настоящее время очередной виток реформы военной подготовки при гражданских вузах основан на фундаменте правовых наработок современной России и направлен на создание унифицированной структуры, устойчивой и гибкой в реальных условиях к систематическим изменениям требований к количественным и качественным показателям подготовки офицеров запаса. В 2019 году распоряжением Правительства Российской Федерации взамен упразднённых военных кафедр, факультетов военного обучения и учебных военных центров в России создано 93 военных учебных центра [13].

Анализируя содержание этапов зарождения, становления и развития системы подготовки офицеров запаса (системы военной подготовки в гражданских вузах), можно выявить некоторые неотъемлемые свойства функционирования этой системы:

1. Система военной подготовки в гражданских вузах по-прежнему остаётся востребованной жизненной необходимостью сохранения и защиты государства (являясь одной из форм военной подготовки, частью военного образования, эта система неотъемлемо имеет свою долю в подготовке кадровых военных, но в тоже время остаётся основой создания мобилизационного резерва).

2. Система военной подготовки в гражданских вузах, равно как и система образования в целом (в том числе военное образование), отражает и немедленно реагирует на любые внутриполитические процессы в государстве. Совершенно очевидно наличие взаимовлияния системы образования и студенчества, государства и молодёжи. Отношение граждан к государству, к его Вооружённым силам - это очень чуткий критерий, показатель здоровья государства и политической зрелости граждан.

Оценивая указанные свойства, сформулируем принципы, лежащие в основе развития системы подготовки офицеров запаса:

1. Система военной подготовки в гражданских вузах должна совершенствоваться с развитием науки и техники, должна отвечать современным технологическим требованиям подготовки студентов.

2. Профессорско-преподавательский состав в системе военной подготовки в гражданских вузах должен обладать высокими, постоянно совершенствующимися квалификациями, отвечающими современным требованиям. 
Кучаев В. А.

ИСТОРИЧЕСКИЙ ОПЫТ И ЕГО ЗНАЧЕНИЕ В СОЗДАНИИ, СТАНОВЛЕНИИ И РАЗВИТИИ СИСТЕМЫ

ПОДГОТОВКИ ОФИЦЕРОВ ЗАПАСА В РОССИИ НА СОВРЕМЕННОМ ЭТАПЕ ЕЁ РЕФОРМИРОВАНИЯ

3. Система военной подготовки в гражданских вузах, имея мощную, постоянно обновляемую учебно-материальную базу, должна гибко реагировать на качественные и количественные изменения показателей государственного заказа по имеющимся воинско-учётным специальностям, а при необходимости иметь потенциал для изменения и дополнения воинско-учётных специальностей в конкретном вузе.

4. Система военной подготовки в гражданских вузах была и остаётся форпостом военнопатриотического воспитания граждан, не только непосредственно обучающихся по программам военной подковки, но и всех студентов вуза.

Система военной подготовки в своём развитии функционирует и совершенствуется на перечисленных принципах. Деградирует эта система, приходит в упадок или уничтожается вовсе только в тесной взаимосвязи и вместе с системами высшего и военного образования, вместе с государственностью. В истории России мы дважды наблюдали регресс, упадок (вплоть до уничтожения) системы подготовки офицеров запаса.

Процесс же возрождения в обязательном порядке опирается на достижения предыдущего этапа. Как бы негативно ни относились большевики к «пережиткам царизма», основные принципы организации подготовки офицеров запаса, элементы её форм пришлось позаимствовать, как было показано, из системы образования дореволюционной России.

Очевидно, что эффективное достижение целей в реформировании системы военной подготовки в гражданских вузах на современном этапе возможно только при выполнении следующих условий:

- чёткой формулировки целей и задач проводимых реформ;

- проведения всестороннего анализа прошедших социально-политических изменений, прогнозирования дальнейших векторов в эволюции системы при законотворчестве и совершенствовании её правовой основы;

- вдумчивого использования исторического отечественного и зарубежного опыта создания и всестороннего обеспечения системы подготовки офицеров запаса.

Действительно, несомненная актуальность вопроса военной подготовки в гражданских вузах (как предмета нашего изучения) уходит корнями в далёкое прошлое. Это значит, что возникновение, развитие и преобразование структуры и содержания военной подготовки требует системного изучения, осмысления в контексте тех или иных исторических событий. Очевидно, что именно такой подход к изучению данного вопроса позволит максимально эффективно проводить реформирование, объективно оценивать происходящие при этом процессы, уточняя векторы дальнейших изменений, необходимость и степень дополнительных управленческих воздействий и точки приложения силы для их реализации.

\section{ЛИТЕРАТУРА}

1. Кафедры уйдут в центры. В вузах военная подготовка студентов сокращена не будет // Редакция «Российской газеты» [Электронный ресурс]. - Режим доступа: https://rg.ru/2018/06/17/v-minoborony-rasskazali-oreforme-voennyh-kafedr-pri-vuzah.html (дата обращения: 24.03.2019).

2. Распоряжение Правительства Российской Федерации от 13 марта 2019 г. № 427-р // Официальный интернет-портал правовой информации [Электронный ресурс] - Режим доступа: http://publication.pravo.gov.ru/Document/View/0001201903150017?index=0\&rangeSize=1 (дата обращения: 24.03.2019).

3. Лейтенант из центра. Военные кафедры вузов станут учебными центрами // Редакция «Российской газеты»: интернет-портал «Российской газеты» [Электронный ресурс]. - Режим доступа: https://rg.ru/2018/06/05/voennye-kafedry-i-fakultety-grazhdanskih-vuzov-stanut-uchebnymi-centrami.html (дата обращения: 24.03.2019).

4. Закрытие военных кафедр приведёт к сокращению числа офицеров запаса // Информационное агентство «Накануне.RU» [Электронный ресурс]. - Режим доступа: https://www.nakanune.ru/articles/114041/ (дата обращения: 24.03.2019). 
5. Кунбутаев, Л. М. Методологические основы функционирования и развития военного обучения студентов в условиях проводимых в России реформ. Проблемы подготовки военных специалистов в гражданских вузах России / Л. М. Кунтубаев, А. А. Тарасов, В. Н. Юлин. - М.: МЭИ, 1993. - С. 8-48.

6. Машкин, Н. А. Высшая военная школа Российской империи XIX - начала XX века / Н. А. Машкин. M., 1997. $-347 \mathrm{c}$.

7. Ховрина, Л. Н. Гуманизация в военном образовании в дореволюционной России в период с 1700 по 1917 год: автореф. дис. ... докт. пед. наук / Ховрина Людмила Николаевна. - М., 1996. - 44 с.

8. Фильков, С. М. Система военной подготовки в гражданских вузах: теория и практика функционирования и совершенствования: моногр. / С. М. Фильков. - М., 2002. - 14 с.

9. Фонд «Русская Цивилизация», 2004. Рустрана [Электронный ресурс]. - Режим доступа: http://рустрана.pф/7758/Ustav-ratnih-pushechnih-i-drugih-del-kasaemih-voennoy-nauki (дата обращения: 24.03.2019).

10. Сайт историка Сергея Владимировича Волкова [Электронный ресурс]. - Режим доступа: http://swolkov.org/tro/index.htm (дата обращения: 24.03.2019).

11. Об учебных военных центрах, факультетах военного обучения и военных кафедрах при федеральных государственных образовательных учреждениях высшего профессионального образования: распоряжение Правительства РФ от 06 марта 2008 г. № 275-р [Электронный ресурс]. - Режим доступа: http://www.consultant.ru/document/cons_doc_LAW_75357/(дата обращения: 24.03.2019).

12. Об обучении граждан Российской Федерации по программе военной подготовки в федеральных государственных образовательных организациях высшего образования: постановление Правительства РФ от 06 марта 2008 г. № 152 (ред. от 28 сентября 2018 г.) вместе с «Положением об учебных военных центрах при федеральных государственных образовательных организациях высшего образования», «Положением о факультетах военного обучения (военных кафедрах) при федеральных государственных образовательных организациях высшего образования». Доступ из справ.-правовой системы «КонсультантПлюс».

13. О военных учебных центрах при федеральных государственных образовательных организациях высшего образования: распоряжение Правительства РФ от 13 марта 2019 г. № 427-р. Доступ из справ.-правовой системы «КонсультантПлюс». 